\title{
Toy Art como ferramenta interdisciplinar para o ensino de arte e Biologia Celular
}

\author{
Marcelo Alberto Elias \\ Instituto Federal do Paraná (IFPR) \\ (marcelo.elias@ifpr.edu.br) \\ Luiz Herculano de Sousa Guilherme Guilherme \\ Instituto Federal de Santa Catarina (IFSC) \\ (luis.guilherme@ifsc.edu.br) \\ Fernanda Maria Trentini Carneiro \\ Instituto Federal de Santa Catarina (IFSC) \\ (fernanda.trentini@ifsc.edu.br) \\ Hendrie Nunes \\ Instituto Federal de Santa Catarina (IFSC) \\ (hendrie.nunes@ifsc.edu.br)
}

\begin{abstract}
Resumo: A Didática, dentro das mais diversas áreas do saber nos dias atuais, têm, muitas vezes, afastado os estudantes da construção do conhecimento, com a facilidade digital, por encontrar tudo pronto e rápido, os alunos muitas vezes perdem o interesse e, até mesmo, a motivação em participar ativamente das aulas. Nesse contexto, o ensino de Biologia celular não está isento dessa situação, por muitas vezes tratar de temas complexos e abstratos para os estudantes, o mais fácil é buscar o conceito pronto. Com o enfoque nesse cenário surgiu uma proposta interdisciplinar entre Biologia e Arte na construção de um Toy Art, usando como modelo uma célula com suas respectivas características e estruturas, buscando, dessa forma, promover uma interação e uma apropriação de conceitos mais próximas e significativas aos estudantes. A atividade interdisciplinar contou com dois professores de Biologia, uma professora de Arte e cerca de 95 alunos, estando esses cursando o segundo semestre dos Cursos Técnicos integrados em Informática e Química, sendo que os resultados foram analisados de maneira qualitativa ao final da atividade. Por meio desse movimento, foi possível observar a importância da autonomia dos estudantes como fator motivacional no processo de construção do conhecimento, uma vez que foram os alunos que escolheram seus tipos celulares e que Toy Art iriam desenvolver. Por fim a interdisciplinaridade mais uma vez mostrou-se sólida e fundamental para o processo de ensino e aprendizagem.
\end{abstract}

Palavras-chave: Interdisciplinaridade; Biologia celular; Arte.

\section{Toy Art as an interdisciplinary tool for teaching art and cell biology}

\begin{abstract}
The Didactics, within the range of one of the most diverse areas of knowledge nowadays, have often removed students from the knowledge building process, especially because of the digital ease, in that way finding everything ready and fast. Students often lose interest and even motivation to participate actively in class. In this context, the teaching of cellular biology is not an exempt from this situation since it often deals with complex and abstract themes for students. To such a degree where students find it easier the easier to seek the concept ready. Focusing on this scenario, an interdisciplinary proposal between Biology and Art emerged in the construction of a Toy Art, using as a model a cell with its respective characteristics and structures, therefore with the purpose to promote an interaction and an appropriation of concepts closer and more meaningful to the students. The interdisciplinary activity counted on two Biology professors, an Art teacher and about 95 students, being those taking the second semester of the Technical Courses integrated in Informatics and Chemistry, and the results were analyzed in a qualitative way by the end of the activity. Through this movement, it was possible to observe the importance of student autonomy as a motivational factor in the process of , Janeiro/Junho 2019.
\end{abstract}


knowledge construction, since it were the students who chose their cell types and the Toy Art they would develop. Finally, interdisciplinarity has once again proved to be a solid and fundamental method for the teaching and learning process.

Keywords: Interdisciplinarity; Cell biology; Art.

\section{INTRODUÇÃOO}

ScientiaTec: Revista de Educação, Ciência e Tecnologia do IFRS, v.6, n.1, p: 13-19

O grande desafio nos dias atuais têm sido tornar o ambiente escolar, em especial a sala de aula, um local atrativo para os estudantes. Assim, para que isso aconteça professores e equipe pedagógica precisam voltarem-se constantemente para novos recursos que promovam maior interação entre os sujeitos e que sejam facilitadores da aprendizagem assim como motivacionais estreitando os laços entre aluno e professor. (SOUZA,2016)

Essa necessidade de novos recursos é reforçada no ensino de Biologia celular, pois muitas vezes esse se torna desgastante ao aluno por estar carregado de nomenclaturas complexas e estruturas somente visíveis em figuras nas quais 0 professor demonstra e o aluno deve "acreditar" que elas existam.

Dentro da gama de conceitos da Biologia celular, optou-se pelo conceito de célula que segundo Alberts et al.(2011): a célula é a unidade morfofisiológica fundamental de todo organismo vivo, apresentando em sua composição elementos químicos arranjados para uma funcionalidade específica, além formas e tamanhos diferenciados.

Assim o conceito de célula, fundamental para todo entendimento da Biologia nas suas diversas áreas também precisa ser ressignificado pelos estudantes.

Dessa forma, os professores Marcelo Alberto Elias, Hendrie Nunes e Fernanda Maria Trentini Carneiro resolveram unir, de maneira interdisciplinar, suas respectivas disciplinas de Biologia e Artes para construção de um "Toy Art" com base em modelos celulares.

Conceito de toys arts, de acordo com Zoccoler (2009), "surgi[...]em meados dos anos 90 quando grifes de streetwear japonesas como Bounty Hunter e A Bathing Ape começaram a fabricar bonecos para promover suas roupas". Contudo, o conceito transformou-se em uma tendência na área de arte, além do design. $O$ modelo artístico é considerado um brinquedo de arte colecionável e personalizado, sendo confeccionado com diferentes materiais, como vinil e tecido, e temas específicos, 
sendo estes personagens de filmes e séries ou elaborado como brinquedos customizados, conforme o consumidor. Com uma estética divertida e atraente, o mesmo na atividade interdisciplinar teve como propósito representar os modelos celulares em formato de toy art sem perder as características celulares. O conteúdo de Biologia foi a referência visual para sua elaboração. Todavia, os alunos pesquisaram exemplos artísticos para conhecer e compreender o propósito e reconhecer conceitos da arte contemporânea abordados na disciplina de arte.

Além do toy art, o conceito de proposição artística foi destacado nesta atividade durante a disciplina de Arte, uma vez que ele tem o intuito do artista propor ao espectador sua interação com a obra. Enquanto proposição artística, o objeto criativo, ao ser exposto, proporcionou ao público a sua interação, em que puderam manusear, "brincar" com o produto produzido e perceber as características do objeto, que envolveu arte e biologia. Acreditamos que a elaboração de um objeto criativo, por meio do ensino de Arte, propõe que o aluno crie e realize a atividade de maneira criativa, crítica e reflexiva. Na perspectiva de Archer (2001, p, 235), "observar a arte não significa "consumi-la" passivamente, mas tornar-se parte de um mundo ao qual pertencem essa arte e esse espectador. Olhar não é um ato passivo; ele não faz que as coisas permaneçam imutáveis". É olhar, analisar, refletir e reconhecer a arte como um campo de conhecimento, de criação, de experimentação.

Para Fazenda (1994) quando falamos em interdisciplinaridade, estamos de algum modo nos referindo a uma espécie de interação entre as disciplinas ou áreas do saber. Assim, o objetivo da atividade foi promover interação entre as disciplinas, os conteúdos abordados em sala de aula e também entre os alunos, por meio da realização da pesquisa teórica, dos materiais a serem utilizados na atividade, de composição visual e sua apresentação.

\section{METODOLOGIA}

A atividade envolveu cerca de 95 alunos da segunda fase dos cursos técnicos Integrados em Química e Informática do Câmpus Gaspar - Instituto Federal de Santa Catarina do segundo semestre de 2017. Os alunos foram divididos em grupos, que ficaram responsáveis pela criação e pela obtenção dos materiais diversificados para a confecção do toy art. 
Cada grupo ficou responsável pela confecção de um toy art, passando pelas seguintes etapas: 1) Escolha do tipo celular: os grupos orientados pelos professores de Biologia puderam escolher através de pesquisa livre os tipos celulares existentes aquele que Ihes chamassem mais atenção. 2) Definição artística: nessa etapa os grupos orientados construíram a ideia do brinquedo. 3) Escolha do material: ainda sob a orientação da professora de arte, os alunos definiram os materiais mais apropriados para execução de seus projetos. 4) Construção: nesse momento, sob a orientação de todos os professores envolvidos, os grupos deram forma aos seus protótipos, sempre lembrados de que a forma deveria ser a mais parecida com a célula original e que a proposta era ser um brinquedo. 5) Finalização: nessa etapa, os estudantes tiveram que sintetizar de maneira clara e objetiva, em um pequeno cartaz, algumas informações sobre aquele tipo celular, tais como: imagem, tamanho real, localização e função. 6) Apresentação: por fim, os estudantes realizaram a montagem da exposição no hall de entrada do auditório, de forma que seu objeto criativo e seu cartaz fossem expostos de maneira organizada e acessível ao espectador.

Para a confecção do produto, os estudantes providenciaram os seguintes materiais: feltros coloridos, tecidos diversos e coloridos, botões, EVAs coloridos, agulha, linha, espuma para enchimento, velcro para fixar ou desafixar alguns detalhes, linhas de tamanhos e cores diferentes, olhos de plástico, cola, tesoura e cola quente. Ao escolherem o tipo celular, com base na referência visual, os estudantes elaboraram um esboço do toy art no papel com as descrições dos materiais que seriam aplicados. Posteriormente, a primeira etapa foi definir o tamanho do tipo celular. Este tamanho deveria ter no mínimo $30 \mathrm{~cm}$. Definido, recortaram a primeira estrutura em feltro, sendo o "corpo" da célula em duas partes. Em seguida, recordaram os detalhes celulares, em tecido, feltro e selecionaram outros materiais para destacar os detalhes, como botões, por exemplo. Em seguida aplicaram esses detalhes nas partes da primeira estrutura com cola e/ou costura, para então costurarem essas duas partes nas bordas, deixando uma abertura para o enchimento. Após o preenchimento, fecharam a abertura com costura. Para finalizar aplicaram os detalhes faltantes, como olhos e boca, por exemplo. De qualquer forma, todos os brinquedos iniciaram a partir da estrutura maior da célula, posteriormente, aplicarem os detalhes. A escolha para o formato do toy art foi livre, podendo ser personagem, monstro, super herói, ser imaginário, desde que apresentassem as características do tipo celular e a possibilidade de manuseio. 
A atividade foi avaliada de maneira qualitativa que segundo Pearce (2012), deve ser rigorosa, exigindo trabalho intenso e investigadores treinados uma vez que consome muito tempo. As informações para análise foram coletadas através do registro feito pelos professores envolvidos em aula posterior a atividade.

\section{RESULTADOS E DISCUSSÃO}

Após todas essas etapas, os trabalhos foram organizados no hall de entrada do anfiteatro da Instituição acompanhado de seus cartazes explicativos, pois em alguns momentos os alunos estavam presentes para explicar suas obras e em outros momentos os visitantes podiam conhecer os projetos sem a necessidade de mediação. As obras ficaram expostas no campus durante todo o mês de Outubro de 2017, possibilitando assim que servidores, alunos, responsáveis e até a comunidade local pudessem ter contato com as mesmas, a fim da exposição ocorreu na Semana Nacional de Ciência e Tecnologia (SNCT), onde mais de 350 visitantes externos ao IFSC puderam conhecer o trabalho possibilitando então uma popularização mais ampla da atividade. Tanto os alunos quanto os participantes e visitantes da SNCT puderam prestigiar e participar da exposição do hall, interagindo assim com o objeto criativo.

Os modelos celulares escolhidos para confecção do Toy art foram, célula de paneth , pneumócito, eosinófilo, Paramecium sp, célula glandular, adipócito, ependimócito, célula epitelial da mucosa oral, condrócito, ovócito, célula , espermatozoide, melanócito, neurônio, célula muscular estriada e célula tronco.

Figura 1: Alguns exemplos confeccionados pelos estudantes. 


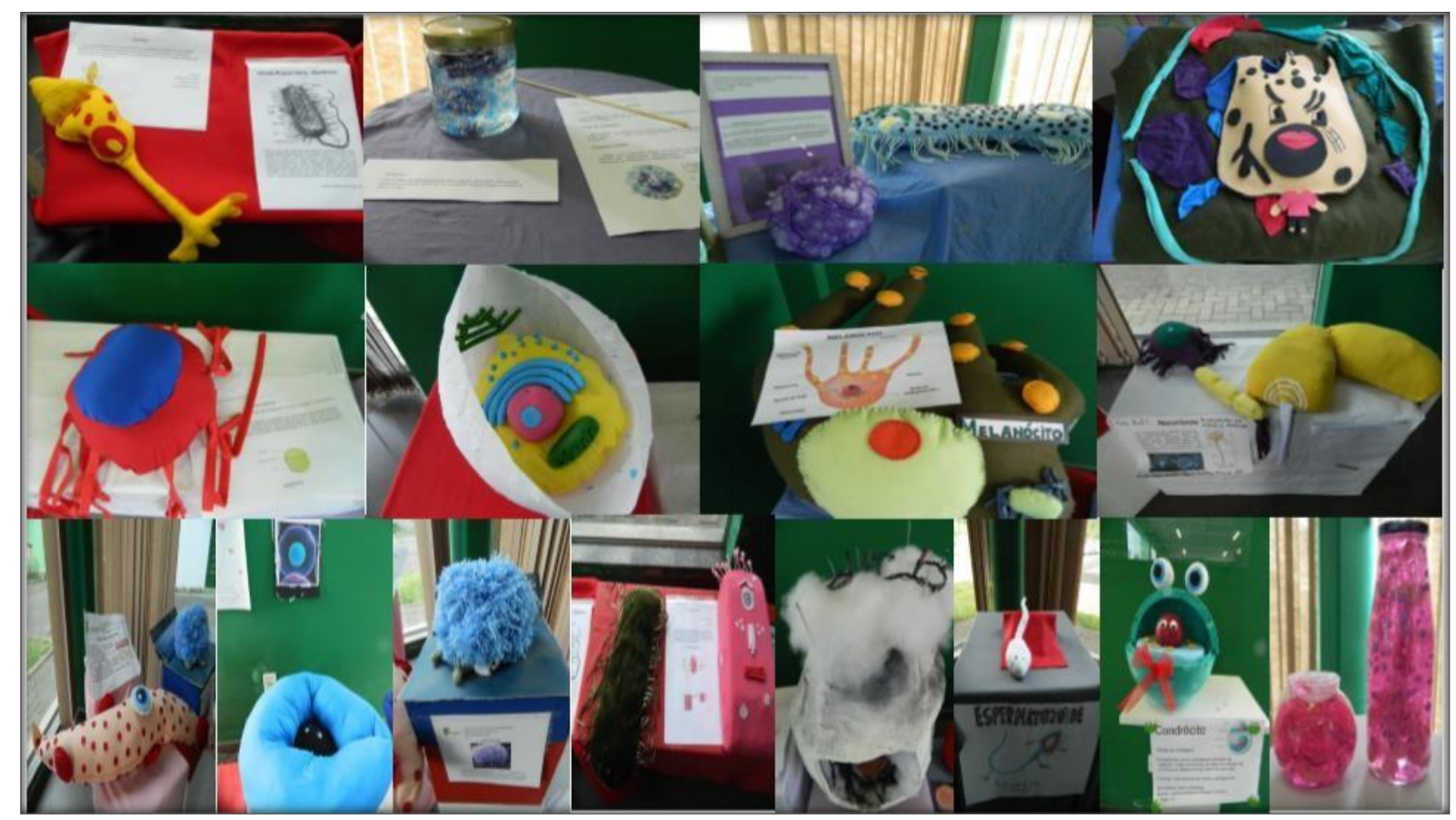

Fonte: Crédito dos autores.

Após a finalização da atividade alunos e professores realizaram uma análise crítica da mesma de forma oral e espontânea, onde ficou evidenciado que $100 \%$ dos alunos consideram a atividade positiva para o processo de aprendizagem destacando, em especial a atratividade que a mesma proporcionou a eles.

\section{CONCLUSÃO}

A experiência docente vivenciada nesse trabalho interdisciplinar e entre turmas mostrou-se bastante gratificante para todos os envolvidos, em avaliação coletiva partilhada pós-atividade pelos professores executores, acompanhados de seus alunos envolvidos, os mesmos puderam verificar que a apropriação de conceitos pode-se dar de formas muito variadas e, até mesmo, não convencionais e que o processo de ensinar e aprender nem sempre precisa seguir padrões pré-

estabelecidos. Observamos que o toy art ficou próximo da realidade dos alunos, pois se encontravam exemplos desses brinquedos de arte no contexto em que vivenciavam, como jogos e seriados. O brinquedo produzido pelos alunos, desde a criação, a confecção e a apresentação, possibilitou o desenvolvimento, a descoberta e a valorização de suas habilidades. Acreditamos que a interdisciplinaridade possibilitou que os conteúdos trabalhados em cada disciplina fossem reconhecidos durante o processo criativo e, posteriormente, com o resultado da atividade. Ela 
reforça as singularidades de cada disciplina e possibilita que se alcance em um objetivo comum os conteúdos abordados. Assim, a equipe executora deste trabalho lança a todos aqueles que estão inquietos com o mecanismo convencional de ensino/aprendizagem envolvidos como a Educação, uma sugestão: APROPRIEM-SE DA INTERDISCIPLINARIDADE.

\section{REFERÊNCIAS}

ALBERTS, B.; BRAY, D.; JOHNSON, A. et al. Fundamentos da Biologia Celular. uma introdução à biologia molecular da célula $3^{\text {a }}$. ed. Porto Alegre: Artes Médicas Sul. 2011.

ARCHER, M. Arte contemporânea. Uma história concisa. São Paulo: Martins Fontes, 2001.

FAZENDA, Ivani C. A. Interdisciplinaridade: história, teoria e pesquisa. $11^{a}$ ed.

Campinas: Papirus, 2003.

PEARCE, L. D. (2012), Mixed methods inquiry in Sociology , American Behavioral Scientist, 56 , 829-848. DOI : $10.1177 / 0002764211433798$

SOUZA, S. E. O uso de recursos didáticos no ensino escolar. In: I ENCONTRO DE PESQUISA EM EDUCAÇÃO, IV JORNADA DE PRÁTICA DE ENSINO, XIII SEMANA DE PEDAGOGIA DA UEM, Maringá, 2007. Arq. Mudi. Periódicos. Disponível em: . Acesso em: 22 mar. 2016.

ZOCCOLER, R. V. "Você é um brinquedo". Dando vida a Toy art. Trabalho de Conclusão de Curso. São Paulo: UNESP, 2009. 